\title{
HUBUNGAN EKUITAS MEREK (BRAND EQUITY) DENGAN LOYALITAS PELANGGAN PADA PT. ENSEVAL PUTERA MEGATRADING Tbk. CABANG BENGKULU
}

\author{
1)Sadad Radansyah; ${ }^{2)}$ Nia Indriasari; ${ }^{3)}$ Wagini \\ ${ }^{1,2)}$ Department of Management, Faculty of Economic, Universitas Dehasen Bengkulu \\ 3) Department of Accounting, Faculty of Economic, Universitas Dehasen Bengkulu
}

Email: ${ }^{1)} \frac{\text { Sadadradansyah@yahoo.com; }}{{ }^{2)} \underline{\text { Wagini980@gmail.com }} \text { Indriasari_nia@yahoo.com; }}$

How to Cite :

Radansyah, S. et.al (2020). HUBUNGAN EKUITAS MEREK (BRAND EQUITY) DENGAN LOYALITAS PELANGGAN PADA PT.ENSEVAL PUTERA MEGATRADING Tbk. CABANG BENGKULU. EKOMBIS REVIEW: Jurnal IImiah Ekonomi Dan Bisnis, 9 (1). DOI: https://doi.org/10.37676/ekombis.v9i1.1223

\section{ARTICLE HISTORY}

Received [12 November 2020]

Revised [17 December 2020]

Accepted [27 January 2021]

\section{KEYWORDS}

Brand equity, customer loyalty

This is an open access article under the $C C-B Y-S A$ license

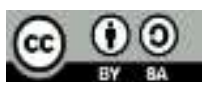

\section{ABSTRAK}

Tujuan penelitian ini adalah untuk mengetahui hubungan ekuitas merek (brand equity) dengan loyalitas pelanggan pada PT. Enseval Putera Megatrading Tbk Cabang Bengkulu. Metode analisis yang digunakan adalah korelasi rank spearman dan uji hipotesis. Berdasarkan analisis korelasi rank spearman terhadap hubungan ekuitas merekdengan loyalitas pelanggan pada PT. Enseval Putera Megatrading Tbk Cabang Bengkuludiperoleh Nilai rho hitung $(\rho)$ antara hubungan ekuitas merek dengan loyalitas pelanggan pada PT. Enseval Putera Megatrading Tbk Cabang Bengkulu adalah 0,841 berada pada interval interprestasi korelasi 0,800-1,000, dengan kriteria sangatkuat, artinya hubungan ekuitas merek dengan loyalitas pelanggan pada PT. Enseval Putera Megatrading Tbk Cabang Bengkulu adalah sangat kuat. Untuk uji hipotesis antara ekuitas merek dengan loyalitas pelanggan pada PT. Enseval Putera Megatrading Tbk Cabang Bengkulu adalah nilai rho hitung lebih besar dari rho tabel $(0,841>0,364)$ sehingga Ho ditolak dan Ha diterima, artinya ada hubungan yang signifikan antara ekuitas merek dengan loyalitas pelanggan pada PT. Enseval Putera Megatrading Tbk Cabang

\section{ABSTRACT}

The purpose of this study was to determine the correlation between brand equity with customer loyalty at Enseval Putera Megatrading Tbk Company BengkuluBranch. The analytical method used is Spearman's rank correlation and hypothesis testing. Based on the Spearman correlation analysis of the 


\begin{abstract}
correlation between brand equity with customer loyalty at
Enseval Putera Megatrading Tbk Company Bengkulu Branchobtained the value of rho $(\rho)$ the correlation between brand equity with customer loyalty at Enseval Putera Megatrading Tbk Company Bengkulu Branchis 0.841 at the interval of the correlation interpretation of $0.800-1,000$, with very strong criteria, meaning the correlation between brand equity with customer loyalty at Enseval Putera Megatrading Tbk Company Bengkulu Branchis very strong. To test the hypothesis between brand equity and customer loyalty at Enseval Putera Megatrading Tbk Company Bengkulu Branchis obtained a calculated rho value greater than rho table $(0.841>$ 0.364 ) so that $\mathrm{Ho}$ is rejected and $\mathrm{Ha}$ is accepted, meaning that there is a significant correlation between brand equity and customer loyalty at Enseval Putera Megatrading Tbk Company Bengkulu Branch.
\end{abstract}

\title{
PENDAHULUAN
}

Seiring dengan perkembangan teknologi yang begitu cepat dan meningkatnya persaingan bisnis, sekarang ini bukan lagi perang kualitas jasa dan produk melainkan juga perang merek. Berbagai usaha dilakukan oleh perusahaan untuk menghadapi persaingan agar mampu menghasilkan keuntungan yang ditargetkan, antara lain perbaikan kualitas barang maupun jasa. Kualitas jasa sudah menjadi standar yang dapat dengan mudah ditiru oleh siapapun, sementara atribut yang susah ditiru adalah merek yang kuat, yang memberikan pedoman, keyakinan, jaminan dan harapan kepada pelanggan bahwa mereka akan terpenuhi kepuasannya. Perkembangan dunia bisnis saat ini membuat semua perusahaan memiliki strategi untuk menghadapi persaingan, salah satunya adalah pemberian nama merek.

Merek adalah suatu atribut yang sangat penting dari sebuah produk yang penggunanya pada saat ini sudah sangat meluas karena beberapa alasan, dimana merek suatu produk berarti memberikan nilai tambah produk tersebut. Pikiran para pelanggan dipengaruhi oleh beragam pesan yang sampai pada angka ribuan pesan dan sering berubah-ubah. Merek tidak hanya kesan-kesannya, tetapi juga harus menempati suatu posisi khusus dalam pikiran untuk benar-benar menjadi sebuah merek. Permasalahannya bila merek tidak mendapat tempat khusus atau berbeda dalam benak konsumen, maka akan memberi kesempatan bagi para pesaing untuk menempati posisi dalam benak konsumen.

Menurut Kotler dan Armstrong (2009:275), merek adalah nama, istilah, tanda, lambang atau desain, atau kombinasi dari semua ini yang memperlihatkan identitas produk atau jasa dari satu penjual atau sekelompok penjual dan membedakan produk itu dari produk pesaing.

Merek mengidentifikasikan suatu produk atau jasa yang dihasilkan oleh suatu perusahaan, identifikasi tersebut juga berfungsi untuk membedakannya dengan produk yang ditawarkan oleh perusahaan pesaing. Merek juga menjembatani konsumen pada saat perusahaan menjanjikan sesuatu kepada konsumen, dengan demikian dapat diketahui adanya ikatan emosional yang tercipta antara konsumen dengan penghasil produk melalui merek pesaing bisa saja menawarkan produk yang mirip, tetapi mereka tidak mungkin menawarkan janji emosional yang sama. 
Kekuatan pesaingan adalah persaingan merek, maka ekuitas merek suatu perusahaan harus semakin kuat. Ekuitas merek adalah nilai tambah yang diberikan pada produk dan jasa. Nilai ini bisa dicerminkan dalam cara konsumen berfikir, merasa dan bertindak terhadap merek, harga, pangsa pasar dan profitabilitas yang dimiliki perusahaan. Ekuitas merek merupakan aset tak berwujud yang penting, yang memilki nilai psikologis dan keuangan bagi perusahaan. Perusahaan yang menghasilkan produk dan jasa, tidak semua nama produk atau jasa otomatis menjadi merek yang kuat, maka perusahaan harus mampu menciptakan suatu nama, simbol ataupun slogan pada suatu merek agar menjadi merek yang prestisius dibenak konsumen. Merek yang prestisius dapat disebut memiliki ekuitas merek (brand equity). Perusahaan yang memiliki merek yang kuat cenderung lebih mudah memenuhi kebutuhan dan keinginan sesuai dengan persepsi pelanggan. Dengan semakin kuatnya ekuitas merek suatu produk maka konsumen akan merasa puas dan semakin kuat pula daya tariknya di mata konsumen untuk mengkonsumsi produk tersebut yang selanjutnya akan membawa konsumen untuk melakukan pembelian secara berulang-ulang, sehingga akhirnya menjadi pelanggan yang setia serta mendatangkan keuntungan bagi perusahaan.

Salah satu perusahaan multi nasional yang memiliki ekuitas merek yang kuat adalah PT. Enseval Putera Megatrading Tbk yang telah memiliki cabang diberbagai Provinsi di Indonesia dimana salah satunya adalah PT. Enseval Putera Megatrading Tbk Cabang Bengkulu. Induk usaha PT. Enseval Putera Megatrading Tbk adalah Kalbe Farma. Ruang lingkup kegiatan PT. Enseval Putera Megatrading Tbk meliputi usaha dalam bidang perdagangan umum dan bertindak sebagai perwakilan atau keagenan. Kegiatan usaha utama Enseval Putera Megatrading adalah sebagai distributor dan pemasok obat-obatan, barang konsumsi, peralatan kedokteran, kosmetik dan barang dagang lainnya.

Dalam menjalankan usahanya, meskipun PT. Enseval Putera Megatrading Tbk telah memiliki ekuitas merek yang kuat, akan tetapi persaingan dibidang distributor dan pemasok obat-obatan, barang konsumsi, peralatan kedokteran, kosmetik dan barang dagang lainnya cukup ketat dan banyak pesaing, sehingga PT. Enseval Putera Megatrading Tbk harus terus berusaha agar PT. Enseval Putera Megatrading Tbk dapat tetap terus bersaing di pasaran, oleh karena itu PT. Enseval Putera Megatrading Tbk yang telah memiliki banyak cabang distributornya tetap harus memberikan kualitas pelayanan yang prima, terus memperluas jangkauan distribusi dan meningkatkan ketersediaan produk dan pemenuhan pesanan secara tepat waktu kepada pelanggan.

\section{LANDASAN TEORI}

\section{Ekuitas Merek (Brand Equity)}

Nilai sebuah produk, nilai sebuah merek sebenarnya didapatkan dari kata-kata dan tindakan konsumennya.Keputusan pembelian konsumen didasarkan padafaktorfaktor yang menurut merek penting, semakin banyak faktor yang dinilai penting maka merek tersebut dapat dikatakan sebagai merek yang bernilai.

Ekuitas merek adalah serangkaian aset dan kewajiban merek yang terkait dengan sebuah merek, nama, dan simbolnya, yang menambah atau mengurangi nilai yang diberikan sebuah produk atau jasa kepada perusahaan dan atau pelanggan perusahaan tersebut (Tjiptono,2011:38). 
Merek bermanfaat bagi produsen dan konsumen. Bagi produsen, merek berperan penting sebagai sarana identifikasi produk dan perusahaan, bentuk proteksi hukum, signal jaminan kualitas, sarana menciptakan asosiasi dan makna unik (diferensiasi), sarana keunggulan kompetitif dan sumber (financial returns) (Tjiptono, 2012:238).

Aaker dalam Ferrina dewi (2009:169) Brand equity atau ekuitas merek adalah sejumlah asset dan kewajiban yang berhubungan dengan merek, namanya, dan simbol, yang menambah atau mengurangi nilai produk atau jasa bagi perusahaan atau bagi pelanggannya. Ekuitas merek adalah nilai tambah yang diberikan pada produk dan jasa.

Ekuitas merek dapat tercermin dalam cara konsumen berpikir, merasa, dan bertindak dalam hubungannya dengan merek, dan juga harga, pang sapasar, dan profitabilitas, yang diberikan, merek bagi perusahaan (Kotler, Keller 2009: 26).

Konsep ekuitas merek mempengaruhi proses keputusan pembelianya itu bahwa merek juga membantu meyakinkan konsumen, dimana mereka membeli produk tersebut. Dengan demikian, merek berkaitan dengan cara konsumen dan membeli barang-barang bukan sekedar sebuah karakteristik barang-barang tertentu.

Indikator dalam ekuitas merek (Durantio, 2011:54) ada empat, yaitu:

1. Kesadaran merek (Brand Awereness)

Kesadaran merek adalah kesanggupan seorang calon pembeli untuk mengenali, mengingat kembali suatu merek sebagai bagian dari suatu kategori produk tertentu. Bagian dari suatu kategori produk perlu ditekankan karena terdapat suatu hubungan yang kuat antara kategori produk dengan merek yang dilibatkan.

2. Asosiasi merek (Brand Association)

Asosiasi merek adalah segala kesan yang muncul di benak seseorang terkait dengan ingatannya mengenai suatu merek akan semakin meningkat dengan semakin banyaknya pengalaman konsumen dalam mengonsumsi suatu merek atau dengan semakin seringnya penampakan suatu merek dalam strategi komunikasinya, ditambah lagi jika kaitan tersebut didukung oleh suatu jaringan dari kaitan-kaitan lain.

3. Kesan Kualitas (Perceived quality)

Kesan Kualitas didefinisikan sebagai persepdi pelanggan terhadap keseluruhan kualitas atau keunggulan suatu produk atau jasa layanan bekaitan dengan apa yang diharapkan oleh pelanggan. Kesan Kualitas ini akan membentuk persepsi kualitas dari suatu produkdi mata pelanggan. Persepsi terhadap kualitas keseluruhan dari suatu produk atau jasa dapat menentukan nilai dari suatu produk atau jasa tersebut dan berpengaruh secara langsung kepada keputusan pembelian konsumen dan loyalitas mereka terhadap merek. Kesan kualitas yang positif akan mendorong keputusan pembelian dan menciptakan loyalitas terhadap produk tersebut. Sebaliknya jika kesan kualitas pelanggan negatif, produk tidak akan disukai dan tidak akan bertahan lama.

4. Loyalitas merek (Brand Loyalty)

Loyalitas merek adalah ukuran dari kesetiaan konsumen terhadap suatu merek. Kepuasan adalah pengukuran secara langsung bagaimana konsumen tetap loyal pada suatu merek. Kepuasan terutama menjadi pengukuran di bisnis jasa . sementara itu loyalitas merupakan hasil akumulasi pengalaman penggunaan produk. Loyalitas merek merupakan salah satu indikator dari ekuitas merek 
yang jelas terkait dengan peluang penjualan, yang berarti pula jaminan perolehan laba perusahaan di masa mendatang. Pelanggan yang loyal pada umumnya akan melanjutkan pembelian merek tersebut walaupun dihadapkan pada banyak alternatif merek produk pesaing yang menawarkan karakteristik produk yang lebih unggul dipandang dari berbagai sudut atributnya.

\section{Loyalitas pelanggan}

Kepuasan pelanggan berhubungan dengan loyalitas pelanggan dan menghasilkan pembelian ulang (repeat purchase), di lain pihak, perusahaan mapan tidak membina reputasi kuat untuk pemuasan pelanggan akan mudah diserang oleh para pesaing baru yang menekankan kualitas dan layanan. Terkadang hanya sedikit perusahaan dapat mengubah keseimbangan persaingan (Wijaya, 2011:25).

Loyalitas merek merupakan sikap pelanggan yang timbul sebagai respon menyenangi suatu merek yang direpresentasikan dalam pembelian yang konsisten terhadap merek itu sepanjang waktu, sedangkan loyalitas toko juga ditunjukkan oleh perilaku konsisten tetapi perilaku konsistennya adalah dalam mengunjungi toko dimana di tempat tersebut pelanggan bisa membeli merek yang diinginkan (Sutisna, 2011:41). Terjemahan loyalitas (Customer Loyalty) menurut Oliver (2010:392) loyalitas adalah komitmen untuk bertahan secara mendalam dengan melakukan pembelian ulang atau berlangganan kembali dengan produk atau jasa terpilih secara konsisten dimasa yang akan datang, meskipun pengaruh situasi dan usaha-usaha pemasaran mempunyai potensi untuk menyebabkan perubahan perilaku. Kualitas layanan yang baik dapat menimbulkan kepuasan dan loyalitas pelanggan. Griffin (2010:4) menyatakan pendapatnya tentang loyalitas pelanggan yaitu konsep loyalitas lebih mengarah kepada perilaku (Behaviour) dibandingkan dengan sikap (Attitude) dan seorang konsumen yang loyal akan memperhatikan perilaku pembelian yang didefinisikan sebagai pembeli yang teratur dan diperhatikan sepanjang waktu oleh beberapa unit pembuatan keputusan. (2010:31):

Adapun karakteristik pelanggan yang loyal antara lain menurut Griffin

1. Melakukan pembelian secara rutin.

2. Membeli diluar lini produk atau jasa.

3. Merekomendasikan kepada orang lain.

4. Tidak terpengaruh daya tarik pelanggan pesaing.

Untuk menjadi pelanggan yang loyal seorang konsumen harus melalui beberapa tahapan. Proses ini berlangsung lama, dengan penekanan dan perhatian yang berbedabeda. Dengan memperhatikan masing-masing tahapan dan memenuhi kebutuhan dalam setiap tahapan tersebut, perusahaan mempunyai peluang yang lebih besar untuk membentuk calon pembeli menjadi konsumen loyal dan klien perusahaan.

Perusahaan yang memperhatikan kepuasan pelanggan dikualifikasikan sebagai perusahaan yang akan mendapatkan beberapa manfaat pokok, dimana Tjiptono (2010:8) mengungkapkan bahwa manfaat yang akan ditimbulkan adalah reputasi perusahaan yang makin positif dimata pelanggan dan masyarakat, serta dapat mendorong terciptanya loyalitas pelanggan memungkinkan bagi perusahaan, meningkatkan keuntungan, maka harmonisnya perusahaan hubungan perusahaan dengan pelanggannya serta mendorong setiap orang dalam perusahaan untuk bekerja dengan tujuan yang lebih baik. 
Untuk menentukan diterima atau ditolaknya hipotesis yang diajukan maka dibandingkan nilai rho $\mathrm{hitung}_{\text {dengan }}$ rho tabel, kemudian dikonsultasikan dengan kriteria pengujian hipotesisnya dengan ketentuan sebagai berikut :

1) Penentuan level of significant $95 \%$ atau alpha (a) $5 \%$

2) $\mathrm{H}_{0}$ ditolak dan $\mathrm{H}_{\mathrm{a}}$ diterima : Jika nilai rho hitung > rho tabel, artinya ada hubungan yang signifikan antara ekuitas merek dengan loyalitas pelanggan pada PT. Enseval Putera Megatrading Tbk Cabang Bengkulu.

3) $\mathrm{H}_{0}$ diterima dan $\mathrm{H}_{a}$ ditolak ; Jika nilai rho hitung < rho tabel artinya tidak terdapat hubungan yang signifikan antara ekuitas merek dengan loyalitas pelanggan pada PT. Enseval Putera Megatrading Tbk Cabang Bengkulu.

Berdasarkan hasil perhitungan uji hipotesis diperoleh sebagai berikut :

Nilai rho hitung $(\rho)$ sebesar 0,841 sedangkan rho tabel 0,364 (terlampir) atau $0,841>0,364$ sehingga Ho ditolak dan Ha diterima, artinya terdapat hubungan yang signifikan antara ekuitas merek dengan loyalitas pelanggan pada PT. Enseval Putera Megatrading Tbk Cabang Bengkulu.

\section{HASIL DAN PEMBAHASAN}

\section{PEMBAHASAN}

\section{Hubungan ekuitas merek dengan loyalitas pelanggan pada PT. Enseval Putera Megatrading Tbk Cabang Bengkulu}

Untuk menganalisis hubungan antara ekuitas merek dengan loyalitas pelanggan pada PT. Enseval Putera Megatrading Tbk Cabang Bengkulu maka peneliti menggunakan analisis korelasi rank spearman. Data yang digunakan dalam korelasi rank spearman merupakan data ordinal dalam bentuk ranking yang diperoleh dari skor jawaban responden sebagaimana terlampir pada lampiran $2-6$. Setelah diketahuinilai $\Sigma b_{i}^{2}$ (lampiran 6) maka dapat dihitung nilai korelasi antara kedua variabel yang diteliti.

Analisis korelasi rank spearman terhadap variabel yang diteliti dapat diketahui dari perhitungan dibawah ini :

Berdasarkan lampiran 6, diketahui bahwa nilai $\Sigma b_{i}^{2}$ adalah711,5 dengan jumlah $\mathrm{n}=30$ sehingga dapat dihitung nilai koefisien korelasi rank spearman sebagai berikut :

$$
\begin{aligned}
\rho & =1-\frac{6 \sum b_{i}^{2}}{n\left(n^{2}-1\right)} \\
& =1-\frac{6(711,5)}{30\left(30^{2}-1\right)} \\
& =1-\frac{4269}{30(900-1)} \\
& =1-\frac{4269}{26970} \\
& =1-0,158
\end{aligned}
$$

Journal Ekombis Review, Vol. 9 No. 1 January 2021 page: 39 - 49| 45 


$$
=0,841
$$

Dari hasil analisis korelasi rank spearman diketahui bahwa nilai $\rho$ (rho) hitung adalah 0,841 tingkat hubungan yang sangatkuat, karena terletak pada interval korelasi antara 0,800 - 1,000, artinya hubungan ekuitas merek dengan loyalitas pelanggan pada PT. Enseval Putera Megatrading Tbk Cabang Bengkuluadalah sangat kuat. Hal ini menunjukkan bahwa setiap peningkatan ekuitas merek akan dapat meningkatkan loyalitas pelanggan pada PT. Enseval Putera Megatrading Tbk Cabang Bengkulu.

\section{Uji Hipotesis}

Untuk menentukan diterima atau ditolaknya hipotesis yang diajukan maka dibandingkan nilai rho ${ }_{\text {hitung }}$ dengan rho tabel, kemudian dikonsultasikan dengan kriteria pengujian hipotesisnya dengan ketentuan sebagai berikut :

1) Penentuan level of significant $95 \%$ atau alpha (a) $5 \%$

2) $\mathrm{H}_{0}$ ditolak dan $\mathrm{H}_{\mathrm{a}}$ diterima : Jika nilai rho hitung > rho tabel, artinya ada hubungan yang signifikan antara ekuitas merek dengan loyalitas pelanggan pada PT. Enseval Putera Megatrading Tbk Cabang Bengkulu.

3) $\mathrm{H}_{0}$ diterima dan $\mathrm{H}_{\mathrm{a}}$ ditolak ; Jika nilai rho nitung $<$ rho tabel artinya tidak terdapat hubungan yang signifikan antara ekuitas merek dengan loyalitas pelanggan pada PT. Enseval Putera Megatrading Tbk Cabang Bengkulu.

Berdasarkan hasil perhitungan uji hipotesis diperoleh sebagai berikut :

Nilai rho hitung $(\rho)$ sebesar 0,841 sedangkan rho tabel 0,364 (terlampir) atau $0,841>$ 0,364 sehingga Ho ditolak dan Ha diterima, artinya terdapat hubungan yang signifikan antara ekuitas merek dengan loyalitas pelanggan pada PT. Enseval Putera Megatrading Tbk Cabang Bengkulu.

Berdasarkan hasil analisis yang telah dilakukan maka diketahui hasil perhitungan korelasi rank spearman dan pengujian hipotesis sebagaimana pada tabel berikut ini :

Tabel 1. Rekap Hasil Penelitian dengan Perhitungan Korelasi dan Uji Hipotesis antara ekuitas merek (X) dengan loyalitas pelanggan (Y) PT. Enseval Putera Megatrading Tbk Cabang Bengkulu

\begin{tabular}{|c|c|c|c|c|}
\hline Variabel & $\begin{array}{l}\text { Rho } \\
\text { hitung }\end{array}$ & Kriteria & $\begin{array}{l}\text { Rho } \\
\text { tabel }\end{array}$ & Kriteria \\
\hline $\begin{array}{l}\text { Ekuitas merek }(\mathrm{X}) \text { dan loyalitas } \\
\text { pelanggan }(\mathrm{Y})\end{array}$ & 0,841 & $\begin{array}{l}\text { Sangat } \\
\text { Kuat }\end{array}$ & 0,364 & Signifikan \\
\hline
\end{tabular}

Sumber : Hasil Penelitian, Diolah, 2020

Dari tabel di atas terlihat bahwa nilai korelasi rank spearman antara ekuitas merek dengan loyalitas pelanggan pada PT. Enseval Putera Megatrading Tbk Cabang Bengkulu diperoleh nilai 0,841 kriteria sangat kuat karena hasil korelasinya terletak pada interval koefisien antara 0,800 - 1,000 sedangkan hasil uji hipotesisnya menunjukkan nilai rho hitung > rho tabel $(0,841>0,364)$ sehingga Ho ditolak dan $\mathrm{Ha}$ diterima artinya ekuitas merek memiliki hubungan yang signifikan dengan loyalitas pelanggan pada PT. Enseval Putera Megatrading Tbk Cabang Bengkulu.

PT. Enseval Putera Megatrading Tbk Cabang Bengkulu merupakan sebuah perusahaan terkemuka yang merupakan cabang dari PT. Enseval Putera Megatrading 
sebagai agen alat kesehatan, obat dan produk kecantikan. Produk kesehatan dan kecantikan merupakan produk yang riskan untuk diperdagangkan karena resiko kesehatan masyarakatlah taruhannya, sehingga apabila alat kesehatan dan kecantikan yang di sediakan oleh PT. Enseval Putera Megatrading Tbk Cabang Bengkulu dalam kondisi yang buruk maka hal ini akan mengakibatkan resiko yang buruk bagi konsumen yang melakukan pembelian pada PT. Enseval Putera Megatrading Tbk Cabang Bengkulu.

Untuk membuat masyarakat tetap memberikan kepercayaan penuh kepada PT. Enseval Putera Megatrading Tbk Cabang Bengkulu sebagai agen alat kesehatan dan kecantikan terkemuka di Bengkulu, maka PT. Enseval Putera Megatrading Tbk Cabang Bengkulu harus berupaya sekuat mungkin untuk mempertahankan ekuitas merek yang dibangun oleh PT. Enseval Putera Megatrading Tbk Cabang Bengkulu dan terus meningkatkannya agar pelanggan yang sudah mempercayakan kebutuhan alat kesehatan maupun kecantikannya dapat selalu setia untuk memilih PT. Enseval Putera Megatrading Tbk Cabang Bengkulu sebagai agen terbaik mereka. Diketahui bahwa apa yang dilakukan oleh PT. Enseval Putera Megatrading Tbk Cabang Bengkulu dalam mempertahankan dan meningkatkan ekuitas merek telah berjalan dengan baik dimana diketahui bahwa upaya PT. Enseval Putera Megatrading Tbk Cabang Bengkulu untuk mempertahankan kekuatan merek pelanggan dalam keadaan baik hal tersebut diketahui dari adanya kesadaran pelanggan untuk memilih PT. Enseval Putera Megatrading Tbk Cabang Bengkulu karena PT. Enseval Putera Megatrading Tbk Cabang Bengkulu agen pertama yang muncul dibenak konsumen ketika konsumen membutuhkan produk kesehatan, obat-obatan maupun kecantikannya.

PT. Enseval Putera Megatrading Tbk Cabang Bengkulu telah menjaga asosiasi merek dengan baik, dimana pelanggan merasa bahwa adanya kecocokan ketika menggunakan produk yang dipasarkan dan hal tersebut memberikan pengalaman yang positif bagi pelanggan PT. Enseval Putera Megatrading Tbk Cabang Bengkulu dan pengalaman positif tersebut akhirnya akan memberikan dampak citra positif bagi perusahaan.

Pelanggan PT. Enseval Putera Megatrading Tbk Cabang Bengkulu merasa bahwa kesan pertama yang diperoleh oleh pelanggan setelah melakukan pembelian pada PT. Enseval Putera Megatrading Tbk Cabang Bengkulu adalah kesan yang positif dimana pelanggan merasa produk yang dipasarkan oleh PT. Enseval Putera Megatrading Tbk Cabang Bengkulu merupakan produk unggulan yang dapat diandalkan dan tidak memberikan kekecewaaan bagi konsumen yang melakukan pembelian produk kesehatan maupun kecantikan pada PT. Enseval Putera Megatrading Tbk Cabang Bengkulu.

Ekuitas merek pada akhirnya menimbulkan loyalitas kepada merek tersebut, dan begitupula dengan apa yang dirasakan oleh pelanggan PT. Enseval Putera Megatrading Tbk Cabang Bengkulu, pelanggan PT. Enseval Putera Megatrading Tbk Cabang Bengkulu merasa bahwa produk kesehatan, obat-obatan dan kecantikan yang ditawarkan oleh agen PT. Enseval Putera Megatrading Tbk Cabang Bengkulu selalu diingat untuk pertama kali apabila pelanggan membutuhkan alat-alat tesebut, dan ini akan menjadi hal positif bagi PT. Enseval Putera Megatrading Tbk Cabang Bengkulu karena pelanggan akan merasa nyaman dan tidak bersedia untuk berpindah ke agen lain yang menawarkan produk serupa.

Loyalitas pelanggan yang dicapai melalui peningkatan ekuitas merek yang dilakukan oleh PT. Enseval Putera Megatrading Tbk Cabang Bengkulu dapat dibuktikan 
2716-4411

dengan adanya pembelian rutin oleh pelanggan tetap PT. Enseval Putera Megatrading Tbk Cabang Bengkulu ketika mereka membutuhkan produk kecantikan, obat maupun kesehatannya.Dengan selalu diingatnya PT. Enseval Putera Megatrading Tbk Cabang Bengkulu sebagai agen produk kesehatan dan kecantikan terpercaya membuat pelanggan pada PT. Enseval Putera Megatrading Tbk Cabang Bengkulu terkadang membeli produk diluar perencanaannya pada PT. Enseval Putera Megatrading Tbk Cabang Bengkulu, karena menganggap bahwa produk yang ditawarkan merupakan produk unggulan.

Loyalitas mendalam yang diberikan oleh pelanggan akan memberikan dampak sangat positif bagi perusahaan dan hal tersebutlah yang saat ini dirasakan oleh PT. Enseval Putera Megatrading Tbk Cabang Bengkulu, karena melalui pelanggan setia PT. Enseval Putera Megatrading Tbk Cabang Bengkulu maka PT. Enseval Putera Megatrading Tbk Cabang Bengkulu dapat melakukan promosi dengan cuma-cuma ini dikarenakan pelanggan yang setia tersebut selalu merekomendasikan kepada pembelinya mengenai informasi-informasi positif PT. Enseval Putera Megatrading Tbk Cabang Bengkulu sebagai agen terpercaya untuk pemenuhan kebutuhan kesehatan dan kecantikan di Kota Bengkulu.

Dampak lain yang juga dirasakan oleh PT. Enseval Putera Megatrading Tbk Cabang Bengkulu dengan setianya pelanggan kepada PT. Enseval Putera Megatrading Tbk Cabang Bengkulu adalah pengaruh yang kuat terhadap kepercayaan pelanggan tentang produk yang dipasarkan oleh PT. Enseval Putera Megatrading Tbk Cabang Bengkulu membuat pelanggan sulit bahkan enggan untuk melakukan pembelian produk yang serupa pada agen-agen lainnya, dan menganggap bahwa PT. Enseval Putera Megatrading Tbk Cabang Bengkulu merupakan agen nomor satu yang tidak dapat disaingi oleh agen lainnya.

\section{KESIMPULAN DAN SARAN}

\section{KESIMPULAN}

Berdasarkan hasil penelitian yang telah dilakukan, maka dapat diambil kesimpulan sebagai berikut :

1. Nilai rho hitung $(\rho)$ antara hubungan ekuitas merek dengan loyalitas pelanggan pada PT. Enseval Putera Megatrading Tbk Cabang Bengkulu adalah 0,841 berada pada interval interprestasi korelasi 0,800-1,000, dengan kriteria sangatkuat, artinya hubungan ekuitas merek dengan loyalitas pelanggan pada PT. Enseval Putera Megatrading Tbk Cabang Bengkulu adalah sangat kuat.

2. Untuk uji hipotesis antara ekuitas merek dengan loyalitas pelanggan pada PT. Enseval Putera Megatrading Tbk Cabang Bengkulu adalah nilai rho hitung lebih besar dari rho tabel $(0,841>0,364)$ sehingga Ho ditolak dan Ha diterima, artinya ada hubungan yang signifikan antara ekuitas merek dengan loyalitas pelanggan pada PT. Enseval Putera Megatrading Tbk Cabang Bengkulu.

\section{SARAN}

Berdasarkan hasil penelitian maka peneliti memberikan saran yang dapat dipertimbangkan berkaitan dengan hasil penelitian yakni: 
1. Diharapkan PT. Enseval Putera Megatrading Tbk Bengkulu, agar mempercepat proses pengiriman barang yang sudah dipesan oleh konsumen supaya konsumen tidak kecewa.

2. Bagian gudang harus menyusun barang sesuai dengan tipe dan merek barang agar lebih memudahkan dalam proses pengecekan stock barang dan memudahkan dalam menyiapkan pesanan.

\section{DAFTAR PUSTAKA}

Durianto, Darmadi et al, 2011. Strategi Pasar Melalui Riset Ekuitas Merek Dan Perilaku Merek. Jakarta : PT. Gramedia Pustaka Utama.

Ferrinadewi. 2009. Merek dan Psikologi Konsumen. Yogyakarta : Graha Ilmu

Griffin. Jill. 2010. Customer Loyalty. Jakarta : Erlangga

Kotler, Philip dan Keller Kevin Lane. 2010. Dasar-Dasar Pemasaran. Alih Bahasa Benjamin Moelan. PT. Indeks:Jakarta.

Kotler, Philip dan Armstrong, Gary. 2009. Principle Marketing. Jakarta : Erlangga

Mowen, John dan Michael Minor. 2011. Perilaku Konsumen. Jakarta : Erlangga

Oliver. 2010. Customer Behavior, Jakarta : Pustaka Sinar Harapan

Oktarlinda, Suzi. 2013. Hubungan Promosi Dengan Loyalitas Pelanggan pada PT. Indosat Tbk Cabang Bengkulu. Skripsi Program Studi Manajemen Universitas Dehasen Bengkulu.

Simamora, Bilson. 2011. 49, Aura Merek : 7 Langkah Membangun Merek Yang Kuat, Jakarta, PT. Gramedia Pustaka.

Sutisna, 2011. Perilaku Konsumen Dan Komunikasa Pemasaran. Jakarta : Balai Pustaka Singarimbun, Masri dan Sofian Effendi. 2009. Metode Penelitian Survey. Jakarta : LP3ES

Sugiyono. 2011. Metode Penelitian Bisnis. Bandung : Alfabeta

Tjiptono, Fandy. 2010. Manajemen Jasa. Yogyakarta : Andi Offset

Tjiptono, Fandy. 2012. Pemasaran strategik. Yogyakarta : Andi Offset.

Wijaya, Tony. 2011. Manajemen Kualitas Jasa. Yogyakarta : Andi Offset 